\title{
THE DETERMINANTS OF KNOWLEDGE TRANSFER FROM UNIVERSITIES TO TOURISM COMPANIES - A CONCEPTUAL MODEL AND RESEARCH PROPOSITIONS
}

\section{MARCIN OLSZEWSKI}

\begin{tabular}{|c|c|}
\hline & $\begin{array}{l}\text { Poznań University of Economics } \\
\text { e-mail: marcin.olszewski@ue.poznan.pl }\end{array}$ \\
\hline $\begin{array}{l}\text { RECEIVED } \\
\text { ACCEPTED }\end{array}$ & $\begin{array}{l}25 \text { March } 2015 \\
8 \text { August } 2015\end{array}$ \\
\hline $\begin{array}{l}\text { JEL } \\
\text { CLASSIFICATION }\end{array}$ & $\mathrm{D} 83, \mathrm{I25}, \mathrm{L} 83, \mathrm{O} 33$ \\
\hline KEYWORDS & knowledge transfer, university, tourism company \\
\hline ABSTRACT & $\begin{array}{l}\text { Acquiring and generating knowledge for product development is critical for the competitiveness of both tourism } \\
\text { destinations and enterprises. The relationships between universities and companies can be treated as weak } \\
\text { ties, and therefore be efficient for knowledge sharing, and to trigger innovativeness. The objective of the paper } \\
\text { is to create a conceptual model of determinants of knowledge transfer from academia to tourism companies. } \\
\text { On the basis of the literature study the research propositions were identified. It is argued that the utilisation of } \\
\text { academic knowledge is affected by both the absorptive capacity of enterprises, and fit between companies and } \\
\text { universities. }\end{array}$ \\
\hline
\end{tabular}

\section{Introduction}

The term "university-industry knowledge transfer" is used to indicate a wide range of interactions, at different levels and involving different activities mostly aimed at the exchange of knowledge and technology, between universities and firms (Rossi, 2010). It is assumed that knowledge is created in academia and subsequently transferred to enterprises for further development (Hjalager, 2002). Previous research suggests that there are 
very limited interactions between academics and practitioners in the tourism industry (Frechtling, 2004; Jordan, Roland 1999; Xiao, Smith, 2007) which has lead to lack of balance between research production and utilisation (Hudson, 2013). According to Cooper (2006: 47) "in many other sectors of the economy, such as primary industries, knowledge transfers efficiently, because the gearing between researcher and business is tight and formalised, which is not the case in tourism". As a consequence, academic research seldom influences the real world of practice (Jenkins, 1999).

Underutilization of academic knowledge can be explained simultaneously by the features and behavior of the senders and recipients of the knowledge. For some, the problem lies with academics who speak to and write only for themselves (Samdahl, Kelly, 1999). Knowledge generated by the academics is often perceived as needlessly complicated or overly sophisticated because people in the tourism industry prefer easy-to-use tools or quick answers (Ritchie, Ritchie, 2002). On the other hand, the knowledge-based view suggests that the extent of knowledge transfer from knowledge generators to knowledge recipients may depend on the recipients' absorptive capacity (Keller, 1996; Zander, Kogut, 1995). The lack or insufficiency of absorptive capacity in a firm hinders the ability to recognise the potential of new ideas arising from interaction with other external knowledge generators (Tsai, 2009; Guisado-González et al., 2013). In the tourism industry, the low level of absorptive capacity is indicated, which can significantly reduce the use of academic knowledge (Cooper, 2006).

The knowledge transfer between universities and companies may also be determined by the existence (or not) of the fit between knowledge creators and its recipients. When knowledge is at least partly tacit, its transfer between different parties often requires the direct assistance of the knowledge creator (Rossi, 2010). This is why it has been argued that proximity among agents - cognitive, geographical, cultural, social - is crucial for knowledge transmission (Balconi et al., 2004; Boschma, 2005). According to Xiao and Smith „on a continuum of knowledge used by academics vis-a -vis practitioners, the closer a user is to the former, the more likely the user will value theoretical richness and the methodological sophistication associated with the creation of knowledge, and vice versa" (2007: 319). Moreover, for the tourism industry, barriers to transfer are related to its nature. It is dominated by small enterprises, fragmented across a variety of activities, and has vocational reinforcers such as poor human resource practices militating against the continuity of absorption (Cooper, 2006). As a result, there is a lack of trust between the knowledge creators and those who might use it, due to the different cultures and vocabularies of differing communities of practice (Davenport, Prusak, 1998; Hjalager, 2002).

The aim of the paper is to create a conceptual model of determinants of knowledge transfer from universities to the tourism companies. The paper opens by reviewing the literature on the determinants of university - industry knowledge transfer. In the second section the research propositions and conceptual model were developed. Finally the overall implications and conclusions are proposed.

\section{Determinants of university - industry knowledge transfer}

If we adhere to the assumption that research results produced by academia and research institutions are important to the business sector, it becomes essential to consider how, and in what form, knowledge is disseminated to enterprises for further development (Hjalager, 2002). The focus on knowledge flows, and potential barriers or facilitators, has attracted a great deal of interest within research and a plethora of perspectives, for nearly 50 years (Sparrow et al., 2009). Previous studies indicate that knowledge transfer occurs only when the appropriate conditions are created. Szulanski (2000) analysed how characteristics of the source of knowledge, the recipient, the context, 
and the knowledge itself affected the transfer. He found that the importance of these factors varied over stages of the transfer process.

The knowledge-based view suggests that the extent of technology spillovers from knowledge generators to knowledge recipients may depend on the recipients' absorptive capacity (Keller, 1996; Zander, Kogut, 1995). Absorptive capacity was originally defined as the "ability of a firm to recognise the value of new, external information, assimilate it, and apply it to commercial ends" (Cohen, Levinthal, 1990: 128). Furthermore, Cohen and Levinthal (1989: 569) emphasised that "a stock of prior knowledge constitutes the firm's absorptive capacity". Absorptive capacity in tourism is an important issue because tourism organisations are particularly dependent on external sources of knowledge when compared with businesses in other sectors (Thomas, Wood, 2014). A systematic review of the literature on innovation in service sector businesses (Carlborg et. al. 2013) confirms the almost complete absence of research into the absorptive capacity of hotels and other tourism businesses in spite of the extensive "mainstream" (notably manufacturing) literature (Thomas, Wood, 2014). For tourism, the concept of absorptive capability is very relevant (Awad, Ghaziri, 2004). It refers to the fact that organisation's ability to expand depends in part on their existing knowledge. Effectively, the greater the stocks, the more effective the assimilation of the new knowledge will be (Cooper, 2006).

The concept of absorptive capacity in the literature is presented in two ways: process related (direct) and subject related (indirect). In the first one, absorptive capacity is a sequence of activities and skills of the company and its members (see Flatten et. al. 2011; Jiménez-Barrionuevo et al., 2011) related to the acquisition, transformation and utilisation of external knowledge. In the subjective approach the concept of absorption capacity is identified with people who have the ability to absorb knowledge. Most often it is assumed that these are university graduates and employees engaged in research and development activities (see. Cohen, Levinthal, 1990; Andriambeloson, Ramangalahy, 2004). In this approach, the absorptive capacity is similar to the concept of the knowledge base.

Previous deliberations on the determinants of knowledge transfer suggest that the existence of a positive relationship between the sender and the entity receiving the knowledge is very important. The presence or absence of this relationship was described as: fit, similarity, proximity or gap (mismatch). All of these approaches assume that the transfer of knowledge occurs when, there is linkage between the entities that will result in the emergence of motivation and conditions to transfer and receive knowledge. The theoretical basis of the concept of fit can be found in social psychology, which suggests that similarity among people in terms of characteristics such as attitudes or personality is associated with better interaction among people (Smith, 2008). The first literature on proximity focused entirely on geographical proximity (Audretsch, Feldman, 1996). Over time other dimensions, such as organisational, institutional, cultural, cognitive, technological, and social proximity have been added (Heringa et al., 2014). Based on the literature, the fit between the sender and the receiver of the knowledge can be grouped into four categories: subjective, objective, time and spatial.

Subjective fit. This fit refers to social proximity and similarity between sender and recipient. It is assumed that, the more one business has in common with another, particularly with respect to the problems that they face and the decisions that they make, the more likely it is that the lessons and examples of one will be of use to the other (Darr, Kurtzberg, 2000). It refers also to the social embeddedness of the collaboration (Heringa, et al., 2014). Social embeddedness involves trust, based on friendship, kinship, personal experiences (Boschma, 2005; Broekel, Boschma, 2012). This kind of proximity can be measured directly by asking about trust and the nature of the relationship (Heringa et al., 2014). It has been suggested that a likely reason for underutilization of tourism research 
by the tourism industry is the lack of communication and understanding between the research community and the tourism sector (Cooper et al., 2006). To enhance cooperation one should reduce the cognitive distance between companies and universities, i.e. to achieve a sufficient alignment of mental categories, to understand each other, utilise complementary capabilities and achieve a common goal (Nooteboom, 2000).

Objective fit. This fit refers to the compliance between form and content of the transferred knowledge and the information needs of the recipient. The delivered knowledge should meet the current and potential information needs of the enterprise. Information is useless if it is not new, but it is also useless if it is so new that it cannot be understood (Nooteboom, 2000). This means that academic knowledge should not only be interesting for the recipients, but also have features which make it easy to understand and use. Hjalager (2002), for example, identifies four systems (types of information) that are relevant to tourism businesses: the trade system (access to market surveys, best practice, certification); the infrastructural system (knowledge about the transport system, traffic); the regulation system (environmental, labour or consumer law); and the technological system (new equipment, software). King, Breen, and Whitelaw (2014) researched the types of information used by small and medium tourism firms. The most important type of knowledge was related to marketing and sales and the least important was knowledge concerning legal and regulatory.

Time fit. On one hand, time fit refers to the ability to deliver up to date knowledge which can be applied at the right time. In the case of the knowledge transfer from universities to companies, it means a quick codification and dissemination of the results. On the other hand, there is growing importance of direct cooperation in common ventures undertaken by both researchers and practitioners. Co-created practices like tours, meetings, discussions and social events brings the world of science and industry closer together (Hoarau, Kline, 2014). With this process, tourism companies are able to see business opportunities and develop new ideas based on knowledge that would not be accessible without these shared practices. It can be argued that facilitative, participative university interaction with SMEs, foregrounds knowledge integration processes rather than other knowledge transfer mechanisms associated with research-led interactions (Sparrow et al., 2009).

Spatial fit. Previous studies do not indicate clearly what is the role of spatial proximity in stimulating the knowledge transfer. The central ideas behind this concept are that proximity is essential in developing stronger levels of trust and common values which are critical for effective knowledge sharing (Shaw, Williams, 2009). Weterings and Ponds (2009) argue that, although most collaborations are geographically proximate, the ones across larger distances are considered more valuable and more often concern knowledge exchange. Geographic similarity may offer more opportunities for transfer because managers may attend regional meetings or because managers in the same area may get better acquainted by virtue of their physical proximity (Darr, Kurtzberg, 2000). The concept of spatial proximity in the tourism industry is associated with the occurrence of so-called learning regions, which are territorial spaces where there is a strong, positive environment that is conducive to collecting learning and knowledge transfer (Shaw, Williams, 2009). Knowledge sharing occurs through different vehicles within learning regions, via inter-firm linkages and partnerships, firms and other knowledge-creating bodies such as universities and government agencies, and informally based exchanges of work-related gossip in both the work-place and social settings within the region (Bathelt et al., 2004; Shaw, Williams, 2009). 


\section{Conceptual framework}

In the light of the discussion presented above what appears interesting is the research problem which is expressed in the following question: what factors determine the use of academic knowledge in tourism industry? The following research propositions should be verified:

Proposition 1. Low absorptive capacity negatively affects the level of academic knowledge utilization.

Proposition 2. Low degree of fit between academics and practitioners has a negative impact on the level of academic knowledge utilization. Fit may be expressed in the following forms:

- P2a. subjective fit. The greater is the subjective fit between universities and enterprises the greater is intensity of the knowledge utilisation. The subjective fit is understood as the ability and motivation to establish a relationship between the sender and the recipient of the knowledge.

- P2b. objective fit. The greater is the objective fit between universities and enterprises the greater is intensity of the knowledge utilisation. The objective fit is understood as the ability to meet recipient information needs by the knowledge sender.

- P2c. time fit. The greater is the time fit between universities and enterprises the greater is intensity of the knowledge utilisation. The time fit is understood as the ability to deliver up to date knowledge at the right time.

- P2d. spatial fit. The greater is the spatial fit between universities and enterprises the greater is intensity of the knowledge utilisation. The spatial fit is understood as the geographical proximity between sender and the recipient of knowledge.

The aforementioned propositions are summarized in the following conceptual model (Figure 1).

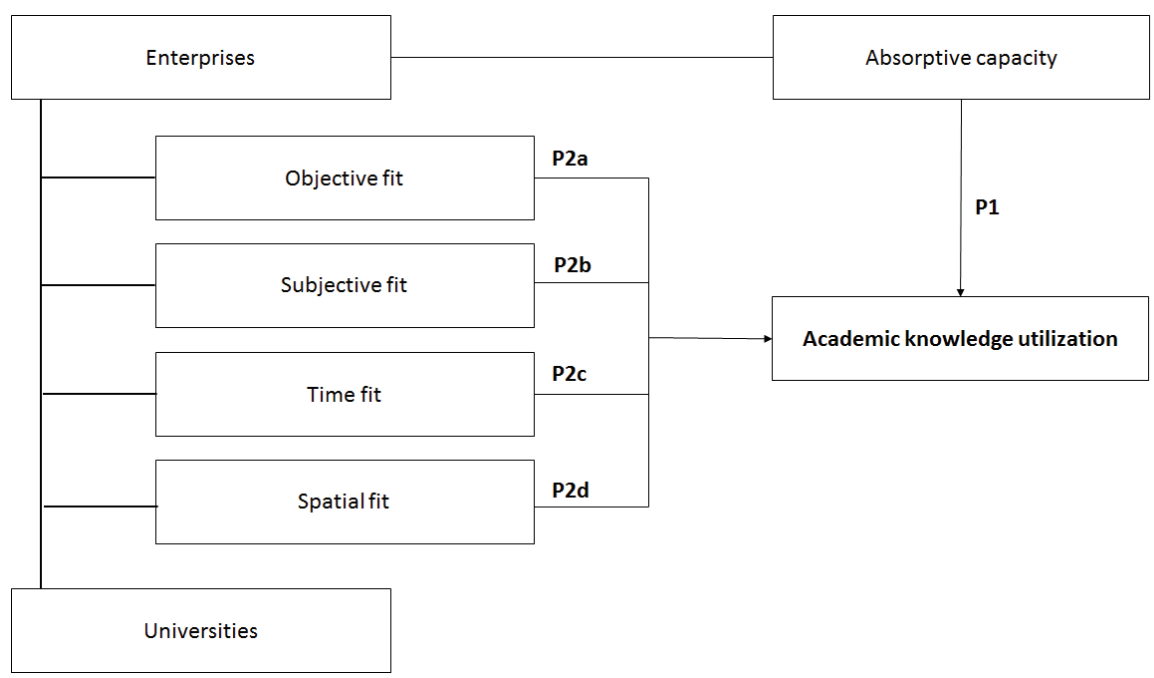

Figulpe 1. Conceptual framework of determinants of academic knowledge utilisation

Source: created by the author. 
The verification of this model enables:

- the indication of the actual academic knowledge utilisation by entities in the tourism industry,

- the identification of the importance of fit between senders and recipients of academic knowledge in terms of four dimensions: subjective, objective, time, spatial,

- the identification of the absorptive capacity of tourism companies and its determinants.

The presented model will be verified on the basis of field research. The empirical research requires to measure primary sources and will be carried out on a sample population. In the study both tourism entities and universities will be included.

\section{Conclusions}

According to Hjalager (2010) there is a need to re-emphasise issues concerning the production and diffusion of academic knowledge into the tourism business community. The main finding of Hoarau and Kline (2014) is that intensive interaction with researchers pays off in terms of organisational learning and development. As a result of this knowledge transfer process, knowledge can be re-combined and innovation can develop (Sparrow et al., 2009).

To explain the determinants of academic knowledge transfer, this project draws upon the absorptive capacity theory (Cohen, Levinthal, 1990); fit theory (Edwards et al., 2006), proximity concept (Boschma, 2005); the theory of knowledge transfer (Szulanski, 2000) and the transfer of innovation (Spencer et al., 2012).

Previous studies on determinants of the academic knowledge utilisation in the tourism industry are inconclusive. Undoubtedly, tourism research is currently under-utilised by the tourism sector and as a consequence; the sector is not as competitive as it could be (Cooper et al., 2006). One possible reason for this is the dissemination of new knowledge generated by research does not currently reach the end users. There is a paradox in which practitioners espouse an appreciation for research but fail to use it (Xiao, Smith, 2007). According to Ritchie and Ritchie, "a great deal of research is being conducted in tourism, but is inefficiently used and rarely exploited to its full potential" (2002: 451).

Therefore, there is a knowledge gap concerning the effects and determinants of university-industry knowledge transfer in the tourism industry. As a result there is the growing need for a more comprehensive analysis, based on primary sources of information. Specifically it can be noted that the proposed research is the first attempt to provide a comprehensive analysis of knowledge transfer from academia to the tourism industry. Moreover, an opportunity arises to link the theory of knowledge transfer (in particular absorptive capacity) and the theory of proximity/fit in one set of tourism research studies. As an interdisciplinary phenomenon, tourism is perfectly suited for research with the use of theories representing different fields of knowledge.

\section{Acknowledgement}

The paper is the result of research project "Knowledge transfer from universities to companies - the determinants and the impact on innovativeness of the tourism industry" financed by the National Science Centre, Poland (decision no. DEC-2014/15/D/HS4/01217). 


\section{References}

Audretsch, D.B. \& Feldman, M.P. (1996). R\&D Spillovers and the Geography of Innovation and Production. The American Economic Review, 86 (3): 630-640.

Balconi, M., Breschi, S. \& Lissoni, F. (2004). Networks of inventors and the role of academia: an exploration of Italian patent data. Research Policy, 33: 127-145.

Bathelt, H., Malmberg, A. \& Maskell, P. (2004). Clusters and knowledge: local buzz, global pipelines and the process of knowledge creation. Progress in Human Geography, 28 (1): 31-56.

Boschma, R. (2005). Proximity and Innovation: A Critical Assessment. Regional Studies, 39 (1): 61-74.

Broekel, T. \& Boschma, R. (2012). Knowledge Networks in the Dutch Aviation Industry: The Proximity Paradox. Journal of Economic Geography, 12 (2): 409-433.

Carlborg, P., Kindstrom, D. \& Kowalkowski, C. (2013). The evolution of service innovation research: a critical review and synthesis. The Service Industries Journal, 34 (5): 373-398.

Cohen, W.M. \& Levinthal, D.A. (1989). Innovation and learning: the two faces of R\&D. The Economic Journal, 99 (397): 569-596.

Cohen, W.M. \& Levinthal, D.A. (1990). Absorptive capacity: a new perspective on learning and innovation. Administrative Science Quarterly, 35: 128-152.

Cooper, C. (2006). Knowledge management and tourism. Annals of Tourism Research, 33 (1): 47-64.

Cooper, C., Jago, L., Carlsen, J. \& Ruhanen, L. (2006). Identification of Inhibitors and Facilitators to Research Adoption in the Tourism Sector. Gold Coast: Sustainable Tourism Cooperative Research Centre STCRC.

Darr, E.D. \& Kurtzberg, T.R. (2000). An Investigation of Partner Similarity Dimensions on Knowledge Transfer. Organizational Behavior and Human Decision Processes, 82 (1): 28-44.

Davenport, T. \& Prusak, L. (1998). Working knowledge: How organizations manage what they know. Boston: Harvard Business School Press.

Flatten, T.C., Engelen, A., Zahra, S.A. \& Brettel, M. (2011). A measure of absorptive capacity: scale development and validation. European Management Journal, 29: 98-116.

Frechtling, D.C. (2004). Assessment of tourism/hospitality journals' role in knowledge transfer: an exploratory study. Journal of Travel Research, 43: 100-107.

Guisado-Gonzalez, M., Guisado-Tato, M. \& Sandoval-Perez, P. (2013). Technological determinants of innovation performance in Spanish hospitality companies: an analysis of the co-existance of innovation strategies. The Service Industries Journal, 33 (6): 580-593.

Heringa, P.W., Horlings, E., van der Zouwen, M., van den Besselaar, P. \& van Vierssen, W. (2014). How do dimensions of proximity relate to the outcomes of collaboration? A survey of knowledge-intensive networks in the Dutch water sector. Economics of Innovation and New Technology, 23 (7): 689-716.

Hjalager, A.M. (2002). Repairing innovation defectiveness in tourism. Tourism Management, 23 (5): 465-474.

Hoarau, H. \& Kline, C. (2014). Science and industry: Sharing knowledge for innovation. Annals of Tourism Research, 46: 44-61.

Hudson, S. (2013). Knowledge exchange: A destination perspective, Journal of Destination Marketing \& Management, 2 (3): 129-131.

Jenkins, C. (1999). Tourism academics and tourism practitioners: Bridging the great divide. In: Contemporary issues in tourism development. Eds. D. Pearce, R. Buttler. London: Routledge (pp. 52-63).

Jimenez-Barrionuevo, M.M., Garcia-Morales, V.J. \& Molina, L.M. (2011). Validation of an instrument to measure absorptive capacity. Technovation, 31: 190-202.

Jordan, D. \& Roland, M. (1999). An examination of differences between academics and practitioners in frequency of reading research and attitudes toward research. Journal of Leisure Research, 31: 166-70.

Julien, P.A., Andriambeloson, E. \& Ramangalahy, C. (2004). Networks, weak signals and technological innovations among SMEs in the land-based transportation equipment sector. Entrepreneurship \& Regional Development, 16 (4): 1-20.

Keller, W. (1996). Absorptive capacity: On the creation and acquisition of technology in development. Journal of Development Economics, 49 (1): 199-227.

King, B.E., Breen, J. \& Whitelaw, P.A. (2014). Hungry for growth? Small and medium-sized tourism enterprise (SMTE) business ambitions, knowledge acquisition and industry engagement. International Journal of Tourism Research, 16 (3): 272-281.

Nooteboom, B. (2000). Learning and innovation in organizations and economies. Oxford: Oxford University Press. 
Ritchie, R.B. \& Ritchie, B. (2002). A Framework for an Industry Supported Destination Marketing Information System. Tourism Management, 23: 439-454.

Rossi, F. (2010). The governance of university-industry knowledge transfer. European Journal of Innovation Management, 13 (2): $155-171$.

Samdahl, D. \& Kelly, J. (1999). Speaking only to ourselves? Citation analysis of Journal of Leisure Research and Leisure Sciences. Journal of Leisure Research, 31 (2): 171-180.

Shaw, G. \& Williams, A. (2009). Knowledge transfer and management in tourism organisations: An emerging research agenda. Tourism Management, 30 (3): 325-335.

Sparrow, J., Tarkowski, K., Lancaster, N. \& Mooney, M. (2009). Evolving knowledge integration and absorptive capacity perspectives upon university-industry interaction within a university. Education + Training, 51 (8/9): 648-664.

Spencer, A., Buhalis, D. \& Moital, D. (2012). A hierarchical model of technology adoption for small owner-managed travel firms: An organizational decision-making and leadership perspective. Tourism Management, 33 (5): 1195-1208.

Szulanski, G. (2000). The process of knowledge transfer: A diachronic analysis of stickiness. Organizational Behavior and Human Decision Processes, 82: 9-27.

Thomas, R. \& Wood, E. (2014). Innovation in tourism: Re-conceptualising and measuring the absorptive capacity of the hotel sector. Tourism Management, 45: 39-48.

Tsai, K.H. (2009). Collaborative networks and product innovation performance: Toward a contingency perspective. Research Policy, 38 (5): 765-778.

Weterings, A. \& Ponds, R. (2009). Do Regional and Non-Regional Knowledge Flows Differ? An Empirical Study on Clustered Firms in the Dutch Life Sciences and Computing Services Industry. Industry and Innovation, 16 (1): 11-31.

Xiao, H. \& Smith, S.L.J. (2007). The use of Tourism knowledge. Annals of Tourism Research, 34 (2): 310-331.

Zander, U. \& Kogut, B. (1995). Knowledge and the speed of the transfer and imitation of organizational capabilities: A empirical test. Organization Science, 6 (1): 76-92.

Cite this article aS: Olszewski, M. (2015). The determinants of knowledge transfer from universities to tourism companies - a conceptual model and research propositions. Szczecin University Scientific Journal, No. 883. Service Management, 16 (2): 111-118. 